International Journal of Linguistics, Literature and Translation

ISSN: 2617-0299 (Online); ISSN: 2708-0099 (Print)

DOI: $10.32996 / \mathrm{jjllt}$

Journal Homepage: www.al-kindipublisher.com/index.php/ijltt

\title{
Languages Spoken and its Influence to the Lexicons and Language Perspectives of ESL Students
}

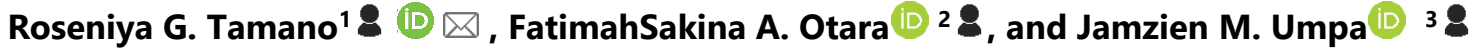 \\ ${ }^{1}$ Associate Professor V, Department of Secondary Teaching, Mindanao State University, Marawi City, Philippines \\ ${ }^{2}$ Teacher 1/Language Coordinator, Soar High Knowledge Foundation Inc., Marawi City, Philippines \\ ${ }^{3}$ College Instructor/School Research Coordinator, Philippine Engineering Agro-Industrial College Inc., Marawi City, Philippines
}

$\triangle$ Corresponding Author: Roseniya G. Tamano, E-mail: roseniya.tamano@msumain.edu.ph

\begin{tabular}{|c|c|}
\hline ARTICLE INFORMATION & ABSTRACT \\
\hline $\begin{array}{l}\text { Received: April 06, } 2021 \\
\text { Accepted: May 05, } 2021 \\
\text { Volume: } 4 \\
\text { Issue: } 5 \\
\text { DOI: } 10.32996 / \text { ijllt.2021.4.5.7 }\end{array}$ & $\begin{array}{l}\text { The linguistic relativity of Sapir-Whorf hypothesis posits how language influences a } \\
\text { person's view of the world. This is where this study is entrenched and attempted to } \\
\text { investigate the extent of influence of English language on the vocabulary of the } \\
\text { selected English Education major students from a state university in Mindanao, } \\
\text { Philippines. Employing survey for their profile, picture-lexicalization, and focus group } \\
\text { discussion, data disclosed that roughly } 70 \% \text { perceived themselves to be very }\end{array}$ \\
\hline $\begin{array}{l}\text { Sapir-Whorf hypothesis, Linguistic } \\
\text { relativity, English language, } \\
\text { lexicons, lexicalization, Meranaw } \\
\text { language. }\end{array}$ & $\begin{array}{l}\text { proficient in their native language; proficient in Filipino, which is the country's official } \\
\text { national language and somewhat proficient in English language. Despite these } \\
\text { perceptions of their proficiency in the languages they speak, picture-lexicalization } \\
\text { method yielded practically } 80 \% \text { of the respondents use the English language } \\
\text { compared to their native and Filipino languages. The participants disclosed that } \\
\text { familiarity with the language played a major part in their picture-lexicalization. Finally, } \\
\text { the FGD further revealed the respondents' view that their native language is a } \\
\text { reflection of their identity. The Filipino language makes them "real" Filipino or their } \\
\text { national identity, while English language is a language of prestige and education that } \\
\text { they can use to communicate with other nationalities. }\end{array}$ \\
\hline
\end{tabular}

\section{Introduction}

Since the American colonisation that brought English language to the Philippines towards the end of 19th century, English has never ceased to establish the prestige and power in the country. This is evident in the rapidly increasing number of speakers which continue to upsurge since the 1925 Board of Educational Survey of the Philippine Islands which illustrated the exceptional English language skills of Filipinos who are not very far from the skills of American native speakers (Borlongan, 2017); positioning the Philippines as among the largest English-speaking nations in the world as claimed by Borlongan (2017), thus placingplacing English on equal-footing with the national language, Filipino, in the 1987 constitution. Thus, it becomes imperative now for Filipinos to learn English and achieve proficiency in the language.

It is observed nowadays that a massive influx of learners uses English language in various domains not just in education, commerce, and government but also in their homes, especially among upper class learners, as manifested in Borlongan (2017) study. But even among the middle and lower classes, people use English language to communicate and express themselves in the social media as seen in the study of Tamano (2012) and Gupta (1997 as cited in Chureson, 2013). With this status quo, it may be inevitable that the language and culture embedded in English language could influence the Filipinos.

People often associate a person's language or how a person uses language based on his or her culture. If a person uses the term "cops" to refer to policemen rather than saying "police" then we can tell that the speaker is an American. However, it should be noted that with the emergence of Philippine English (PhlEng) as a variety of English, then a question worth raising is that what culture is entrenched in the Philippine English? Is it the American culture as colonizers in the past or the Filipino culture? Hence,

\section{K C AL-KINDI CENTER $\mathbf{R}$ D FOR RESEARCH AND DEVELOPMENT} Your gateway to world-class research

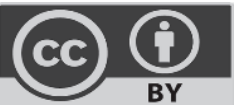

Published by Al-Kindi Center for Research and Development, London, United Kingdom. Copyright (c) the author(s). This open access article is distributed under a Creative Commons Attribution (CC-BY) 4.0 license 
the main objective that this paper attempts to explore is the extent of the influence of English language on the language lexicons of the selected students from Mindanao, by analyzing the words they use in categorizing or identifying objects.

This paper aims to shed light on the influence of English language on the lexicons of selected English major students. The methods used in this study is the picture-lexicalization using the Swadesh list of words, a survey to collect the profile of the respondents, and a focus group discussion. It should be noted that this paper utilized 55 words from the Swadesh list. Therefore, the claim of the extent of influence of English language on the respondents' lexicography is not conclusive but indicative of the influence.

The following research questions were dealt on: 1) What are the languages spoken by the respondents and their perceived proficiency of those languages? 2) What language lexicons are used by the respondents in identifying or naming the pictures shown to them? The next section presents the literature review, methodology, findings, discussion, and conclusion.

\section{Literature Review}

In the introduction of the 2017 Philippine English as a Second Language Journal (ESL) written by Borlongan, he stated that it was the linguist, Llamzon, in 1969 who pointed out an emerging variety of English in the Philippines from his monograph entitled Standard Filipino English. This ground-breaking work received much attention from linguists (Borlongan, 2017) and led to a number of researches on Philippine English and has continuously been a subject of debate among Filipino linguists (RegalaFlores, 2016). For instance, in the words of Borlongan (2017); Gonzales (1972) and Hidalgo (1970) questioned Llamzon's claim of an emerging localized and standardized English variety in the country and the claim of "sizeable base of native local English users" (p.1). Worth noting, nevertheless, is the premise that Philippine English became one of the most pursued research studies on language among Filipino linguists.

\subsection{Language and Culture: its relationship}

There have been claims about the relationship between language and culture and how it fascinates some scholars, according to Wardhaugh (2001). If what was mentioned in the paragraph above, that we learned to categorize the world around us because of our culture, then a culture with no specific term to express a phenomenon, object, or action may have difficulty understanding the subject. For example, the notion about pregnancy, American culture with a strong sense of time, technologically advanced, and a strong culture of labour may not be able to understand Filipinos' cultural and superficial beliefs about the complexities and subtleties of early-stage pregnancy. For English speaking nations, the early stage of pregnancy may be described specifically depending on what the woman experiences such as morning sickness, nausea, cravings, and other symptoms. For Filipinos, the only term used to describe this stage is the word "naglilihi," a term not only limits its definition to what the English language can describe but practices or beliefs that go beyond that.

The relationship between language and culture or how they influence each other can be best deciphered by the Sapir-Whorf hypothesis which emerged during the middle of the 20th century. This hypothesis can be differentiated into weak and stronger versions. Linguistic relativity is the weak version that claims that the structure and the predetermined categories in a language influence a person's view of the world. Yule (2010) calls this "habitual thought" or the way in which we do not necessarily have to analyse or think about the things around us or how we go on with our lives because we conceptualize and categorize things based on the language of our culture. On the other hand, the stronger version is called linguistic determinism which posits that language determines or controls our way of thinking. An example provided in the book of Yule (2010), is the English language which has many names for all colors of the spectrum but Dani of New Guinea only uses "black" and "white" to identify those colors. In other words, according to this hypothesis, if Filipinos are required to learn English as second language, then their perspectives or thoughts can be likened to that of an American or British because of the influence of the language.

\subsection{The influence of English language}

Cholakova (2015) enumerated positive and negative influences of English language. On a positive note, learning English language could lead to academic success especially if English is used solely as the medium of class instruction. This is quite true, for instance, in the Philippines, where English is the language of testing and assessment, including board exams (except for specialize language subjects or courses like Filipino); if learners have good English comprehension skills, then there would be fewer problem in answering questions that are written in English.

The second positive influence mentioned by Cholakova is the impact of English as an international language in political and economic growth and development. The advantage of someone with good communication skills in English is being in-demand in the job market and have the potential to be easily employed in other countries. English language as global lingua franca bridges language barriers. If a Filipino decides to work or go on tour, for instance, in the United Arab Emirates, the language barrier in communication can be lessened if he or she can speak English language. 
As for the negative influence, Crystal (2003 as cited in Cholakova, 2015) has mentioned perhaps the biggest issue of the global dominance of English which is its threat to other languages particularly, the native language of speakers, where it could lead to endangerment. In the case of Filipinos, influence of English led to the emergence of Taglish or the practice of code-switching between English and Tagalog. Taglish, however, seem to have a negative connotation among educated Filipinos. According to Bautista (2009) and Francisco (2012 as cited in Chureson, 2013), foreign visitors who hear Taglish causes "frustrations" because they realize that what they heard was actually not pure English and that the use of this kind of language signifies a speaker's lack of proficiency in the two languages.

Another consequence of the influence of the English language is the Anglicism or the words, phrases or idioms that were borrowed from the English language. This is mainly due to language contact (Stojičić, 2004) and the difficulty of translating English words to the native language (Haller, n.d.); for instance, the word "flash drive" or the USB stick have no equivalent or may not be possibly translated into Filipino. With this age of information and new technologies, most borrowed words, therefore, are Information and Technology (IT) terms (Haller, n.d.). It should be noted nevertheless that as other languages tend to loan words from English, English language itself also went through the process of borrowing from other languages. The last three years of 1980s sought 1,029 English words borrowed from 84 languages (Stojičić, 2004) or an estimated $80 \%$ of English vocabulary (Haller, n.d.). What can be implied in here is that the notion of language influence may occur across languages and not just from English language alone as the global lingua franca.

\subsection{Previous Researches on Language Lexicalization, Use, and Influence}

Related studies that are cited in this section taps on the following research area: language use, influence of English language, and studies on lexicons.

First is the study from Berowa (2016) which investigated the different speech domains in the use of English language among Meranaw students. She found that Meranaw student-respondents "sometimes" use English language in various domains and speech situations in the university, depending on the context of situations (whether formal or informal). For example, they tend to use English when conversing with their college instructor and then use their mother tongue or national language, Filipino, when dealing with university personnel.

Chureson (2013) conducted an interview, spot observations and observation of Filipino media to determine the impact of English as a global language on the Filipino language practices. The findings indicated three offshoots to language modifications: the emergence of Taglish (Tagalog-English), the loss of proficiency in Filipino language, and the lack of purity both in Filipino and English languages.

On the other hand, Ingilan (2016) studied the lexicalization of profanity in Tausug and Kagan languages in Mindanao. The study depicted the significant role of the participants' religion, Islam, in lexicalizing the Tausug and Kagan profanities. This influence of Islam is rooted in the Arabic language (which is the language of Islam as used in the holy book Qur'an and other Islamic scriptures) and is manifested from the loanwords and religious terms taken from Arabic. Moreover, animal references formed part of the profanity and that cursing included expressions of destruction, death, sex, sickness, and assault to the "face."

All researches mentioned in this section are indicative of the influence and relatedness of language, society and culture that English still stands as the most preferred language use in various domains (Berowa, 2016). Thus, resulting in language modifications such as Taglish in the case of the Philippines (Chureson, 2013). Finally, culture does play a part in a person's lexicons, as evident in the influence of religion Islam in the lexicalization of profanity among Tausug and Kagan of Mindanao.

\section{Methodology}

In an attempt to investigate the influence of the English language on the lexicons of the selected college students, this paper used descriptive qualitative and quantitative research design through a researcher-made survey questionnaire, picture-

lexicalization and focus group discussions.

\subsection{Survey}

The survey collected the demographic profile of the respondents as to their age, ethnicity, and languages spoken and their perceived proficiency of those languages.

\subsection{Picture-lexicalization}

Picture-lexicalization is operationalized as the vocabulary word or words used by the participants in expressing or identifying the pictures shown to them. The pictures were taken from the Swadesh list. As cited by Prévot, Chu-Ren, I-Li (n.d.), Swadesh list is a basic core lexicon or vocabulary developed by Moriss Swadesh in the 1950s. The items on the list are considered to have 
provided (at least) a common denominator of the lexicons of the different languages. Thus, it has been "selected for their universality" (p.325) and is basically comprised of terms that "embody direct human experience" (p.326).

In this study, fifty-five (55) lexicons were taken from the Swadesh list. Sixteen (16) animal words, 9 foods (that includes fruits and vegetables), 11 objects used at home, 5 garments, and 14 body parts. In the data gathering and prior to showing each picture to the participants, they were instructed to name or identify the picture using any language they prefer.

\subsection{Focus Group Discussion}

In the FGD, respondents were asked to state their reason for the language they used in identifying the pictures and the results were analyzed using content analysis.

\subsection{The participants}

Using a purposive sampling procedure, 24 college students served as participants in this study.. They were all first-year students taking Bachelor of Secondary Education major in English from Mindanao State University, Marawi City. A state university in the southern part of Mindanao, Philippines. The participants were all aged 18-21 years old. The majority (17 or $70.83 \%$ ) of the participants were of Meranaw ethnicity and only 7 (29.2\%) of them were non-Meranaws: 2 Surigaonons, 1 Waray, and 4 Bisayas.

\subsection{Data Collection and Data Analysis}

In gathering the data, the respondents were asked to fill out first the survey on their profile. Afterwards, picture-lexicalization was conducted. In administering the lexicalization, the respondents were given papers with numbers 1-55. They were asked to write the first word that would come into their mind or word/s that would pop into their head when they see each picture. They were instructed to use any language. To ensure that the teacher would not be a factor to influence them in lexicalizing the pictures (the researcher is the English major instructor of the respondents), Filipino language was used in giving instructions. Filipino since it is the national language and the common language understood by all.

The frequency and percentage are the main statistical tools used to determine the profile and the language used in the picturelexicalization. To measure the perceived proficiency of the languages spoken by the respondents, a rating of 1-5 were asked from them, in which 1 means very proficient to 5 as not proficient but can understand. Picture-lexicalization was analyzed according to the language they used in expressing it. Lexicalized and non-lexicalized were also employed in the analysis of the participants' answer to the pictures shown to them. Lastly, the FGD results were analyzed using content analysis.

\section{Results and Discussion}

The flow of the presentation of the results and findings is based on the order of the research questions. Data revealed that respondents cited five languages they are able to speak: Meranaw, Surigaonon, Bisaya, Filipino and English. The first three languages (Meranaw, Surigaonon and Bisaya) are native languages hence, high proficiency is found in these languages from among the respondents; except one Meranaw respondent who perceived him or herself as somewhat proficient in his or her native language. Further revealed is that nearly $71 \%$ of them are proficient in Filipino language and somewhat proficient in English language respectively. This data means that the respondents' first and second language (L1 and L2), whether it is their native language or the Filipino language, admittedly, consider themselves as not yet proficient in English language but to some extent they are able to speak and understand it. Nonetheless, there are 6 of them who believe they are proficient and one respondent who thinks he or she is very proficient in English.

To ensure that the researcher gave justice to the concept of "English language influence," the first word that came into the mind of the respondents as they see each picture is what the researcher tabulated because the fact that it is the first word (regardless of the language preference) that came into their mind, then it can be assumed that the language they use has influenced them to a certain extent that it becomes automatic in speech and/or in writing. Yule (2010) mentioned the "habitual thought" tendency of linguistic relativity due to language influence. Data disclosed in Table 1 depicts that in all the categories, English by far, with nearly $80 \%$, is the language used by the respondents in naming the pictures shown. Followed by the use of Filipino language and their native language with only a little over $15 \%$ and $7 \%$ respectively.

Table 1. Respondents' language used in picture-lexicalization

\begin{tabular}{lrr}
\hline Categories & \multicolumn{1}{c}{$\boldsymbol{~}$} & \multicolumn{1}{c}{} \\
\hline Animal Lexicalization & & \\
English & 338 & 88.02 \\
Filipino & 33 & 8.59 \\
\hline
\end{tabular}




\begin{tabular}{|c|c|c|}
\hline Native Language & 13 & 3.39 \\
\hline TOTAL & 384 & 100 \\
\hline \multicolumn{3}{|l|}{ Food Lexicalization } \\
\hline English & 155 & 71.76 \\
\hline Filipino & 51 & 23.61 \\
\hline Native Language & 10 & 4.63 \\
\hline TOTAL & 216 & 100 \\
\hline \multicolumn{3}{|c|}{ Objects-at-home Lexicalization } \\
\hline English & 176 & 66.67 \\
\hline Filipino & 50 & 18.94 \\
\hline Native Language & 38 & 14.39 \\
\hline TOTAL & 264 & 100 \\
\hline \multicolumn{3}{|l|}{ Garment Lexicalization } \\
\hline English & 95 & 79.17 \\
\hline Filipino & 15 & 12.5 \\
\hline Native Language & 10 & 8.33 \\
\hline TOTAL & 120 & 100 \\
\hline \multicolumn{3}{|c|}{ Body parts Lexicalization } \\
\hline English & 273 & 81.5 \\
\hline Filipino & 44 & 13.13 \\
\hline Native Language & 18 & 5.37 \\
\hline TOTAL & 335 & 100 \\
\hline Summary & $\boldsymbol{F}$ & $\%$ \\
\hline English & 1037 & 77.42 \\
\hline Filipino & 193 & 15.35 \\
\hline Native Language & 89 & 7.222 \\
\hline Total & 1319 & 100 \\
\hline
\end{tabular}

According to some respondents, the language they use in naming the pictures was because it was "easy to spell" (Respondent 5) and "the easiest way to express idea" (Respondent 11). There are some respondents who use non-lexicalized in naming the pictures. For examples, in the picture of a running dog, some answered by describing what they saw and felt: what's that? Dog on water, Aman my dog, man's bestfriend, bull dog, and brown dog idiots. Other lexicalized are based on what they felt, such as: scary, running and candid. Regardless of the lexicalized or non-lexicalized preferences of the respondents and the way they identified the pictures, what is overwhelmingly prevalent is the use of English language.

Culture does seem to have also influenced some of the respondents in lexicalizing the pictures. When the picture of a pig was shown, some gave the following answers: yucks! Baboy (Filipino equivalent of pig), haram (Arabic word which means forbidden) pig, and pigment. It can be recalled that more than half of the respondents are Meranaws who are also Muslims or followers of the religion of Islam. In Islam, pig is highly considered as a forbidden animal to be eaten; for some Muslims, it is taboo to even mention the word "pig." This implies that the culture attached to the Arabic language, since it is the language of the Islamic scriptures, has also influenced the lexicons of the Meranaws.

During the FGD, most of the respondents stated that familiarity with the language made them use a specific language to identify the pictures. Familiarity for them means they are more comfortable to use; they got used to speaking it, mastery of the language's vocabulary, appropriateness in the context, and what their parents taught them. Just like what Respondent 6 and 10 mentioned about the ease to utter and familiarity:

"I use martilyo because it is easily uttered to me and because it is more familiar to me like in TV, ebooks." (R6)

"I often hear these words and that is why I got used to saying or identifying the object." (R10) 
Some respondents mentioned that they are more familiar with English because it is the language in school, it is versatile and normally used, and there was one who said he/she just simply likes English language. Gleaning from these responses, it can be said that English is indeed the most familiar language to them because of its ease of use in speech and writing and their exposure to it. Compared to their native language, where they tend to have difficulty pronouncing some words and even put it into writing like the case of Meranaw language. However, it should be noted that although English language is more familiar and their preferred language in lexicalizing the pictures, they do not consider themselves to be proficient.

A further look at other languages, the native language, yielded the highest percentage (almost 15\%) in the lexicalization of the objects used at home and lowest in the food and garment lexicalization. As to the objects used at home, this may not be surprising because the native language's de facto domain is basically at home. According to one respondent, he/she uses the native language in some pictures because those are objects they used at home and the language they use at home. On the other hand, it may be difficult for learners to use their native language in lexicalizing the food and garment because some of these words have no equivalent in their native language. For instance, the fruit watermelon or melon is very much the word used by Meranaws in naming that fruit because it has no Meranaw translation. Meranaws tend to just borrow the English word melon or its Filipino equivalent which is pakwan. Borrowing from English language or the Anglicism is one of the consequences of the influence of English on other languages (Stojičić, 2004; Haller n.d.)

As for the Filipino language, its highest percentage is on the food and objects use at home. Again, familiarity played a factor here. For example, the picture of a corn, some respondents answered mais or mais con yelo because it is the common term used when buying a corn. Mais con yelo is a corn in crushed ice poured with milk and sugar being sold in the Philippines. A Filipino citizen would not normally say "corn" to a seller unless it is a foreigner. Meanwhile, the lowest percentage in the use of Filipino language is on the garment lexicalization. Since the respondents mentioned the ease of use in oral and written, it is no doubt that they used the English lexicons in naming the objects like the cap and shoes because they only require one-syllable to utter and write the words. Unlike if they use the Filipino term which is translated as sombrero and sapatos; where it has three syllables. Writing may have played a factor. That is why this paper will recommend that for future study, rather than asking the respondents to write, audio-recorded responses can be tested.

In brief, the influence of English language or other languages on the L1 of the selected students from Mindanao State University is inevitable and may be deemed positive for some because the ultimate goal for these respondents is to achieve mastery of English because their choice of degree implies that they want to be English teachers in the future. Nevertheless, it should be noted that English language learning in the Philippines is not a constraint to learning the American culture because of the varieties of English. In our case, we have the Philippine English. And it is worth mentioning that PhilE lexis has created new coinages that illustrate its "advance state" (Beirmeier, 2017) and has even seen its entries in the Oxford English Dictionary (OED). Salazar (2017) cited that in the middle of the year 2015, 40 new words and senses from PhilE was published by OED words like buko juice, leche flan, presidentiable, halo halo among others. Signifying that PhilE has its own native lexicons that are "equally valid as standard American English."

These all imply that English learners need not be strictly imposed with the teachings of the American standard of English or the British standard for that matter. As to the question whether this PhilE is comprehensible and intelligible to English native speakers or other non-Filipino speakers, The paper of Dita and De Leon (2017) and Dayag (2007 as cited in Dita and De Leon, 2017) indicated a roughly $60 \%$ intelligibility. Contrariwise, the fact remains that although PhilE has not yet achieved its linguistic independence (Collins and Borlongan, 2017), from a lexical point of view, "certainly" it has emerged (Beirmeier, 2017) and may evolve to at least $80 \%$ intelligible to other English speakers in the future.

\section{Conclusion}

This paper shed light on the influence of languages spoken and its influence on the lexicons of the selected English Education college students. Data collected and analysed disclosed that apart from the Filipino and English; Meranaws, Bisaya and Surigaonon as their mother tongue are the languages spoken by the 24 respondents of the study. Furthermore, the data revealed that although the respondents perceived themselves to be "very proficient" in their native languages; "proficient" in Filipino language and "somewhat proficient" only in English, they still used English language in naming or identifying the pictures shown to them. The least language they used in lexicalizing is their native language. Non-lexicalized terms were also found in their responses wherein they described what they saw and felt about the picture. However, whether they used lexicalized or non-lexicalized in identifying the pictures, the fact remains that English was still the language they used in lexicalization of the pictures.

These phenomena suggest that English language has highly influenced the respondents to a certain extent and under certain circumstances. Sapir-Whorf hypothesis' linguistic relativity posits that the structure of one's language, with its predetermined 
categories, tend to influence how a person views the world (Yule, 2010; Wardhaugh, 2001). This may be true with the case of the respondents of this study since these students have been exposed to English language as the medium of instruction and as a subject matter from elementary until high school and it is also the language of their interest being students taking up a degree on English education. Surprisingly, this influence is limited to English and the Arabic language. It was depicted from the data that few students used the Arabic word haram, which means forbidden, in lexicalizing the picture of a pig. It can be recalled that the majority of the respondents are Meranaws whose religion is Islam and Islam forbids the consumption of pigs.

Native language may be the language they use at home and with family and friends. However, the overwhelming frequency of English language in the picture-lexicalization is congruent to the general perceptions of English as the language of education. After their major course class and with the researcher who is also their English instructor, the study was conducted in the school. These may all have contributed to their automatic choice of language in identifying the pictures, not to mention that some pictures shown to them are images of Western people who have blond hair and white skin tone. Hence, this paper highly recommends further studies that would corroborate these findings. Hence, this paper highly recommends further studies that would corroborate these findings with a different context and method but similar objectives.

Funding: This research received no external funding

Acknowledgments: The researchers would like to extend their thanks to their research-buddies, to Sir Jerryk C. Alico and Dr. Wardah D. Guimba. Also to Dr. Grace Rafal, for suggesting the Swadesh list.

Conflicts of Interest: The authors declare no conflict of interest.

\section{References}

[1] Berowa, A. M. (2016). English language use among oral communication meranao students and their language learning orientations: the MSU Marawi case. The Online Journal of New Horizons in Education. 6 (4), 75-79.

[2] Biermeier, T. (2017). Lexical trends in Philippine English revisited. The Philippine ESL Journal. ELE Publishing. 19. 25-44.

[3] Borlongan, A. M. (2017). Contemporary perspective on Philippine English. The Philippine ESL Journal. ELE Publishing. 19. 45-59.

[4] Cholakova, M. (2015). The influence of the English language in a multilingual and a monolingual environment - a comparative

approach. International Journal of English Language Teaching. 3(4). 35-78. Published by European Centre for Research Training and Development UK.

[5] Chureson, O. (2013). The impact of English as a global language on Filipino language practices. International Forum. 16(2). $22-36$.

[6] Collins, P. and Borlongan A. M. (2017). Has Philippine English attained linguistic independence? The grammatical evidence. The Philippine ESL Journal. ELE Publishing. $19.10-24$.

[7] Dita, S. and De Leon, K. (2017). The intelligibility and comprehensibility of Philippine English to EFL speakers. The Philippine ESL Journal. ELE Publishing. 19. 100-116.

[8] Haller, M. (n.d.) The Influence of the English language on other languages.

[9] Ingilan, S. S. (2016). Lexicalization of profanity in Tausug and Kagan languages, Mindanao, Philippines. Univ. of Min. Intl. Mult. Research Journal. 1(2). 140-148.

[10] Prévot, L., Chu-Ren, Huang., and I-Li, S. (2006) Using the Swadesh list for creating a simple common taxonomy. Institute of Linguistics. Academia Sinica Nankang, Taipei, Taiwan 115.

[11] Regala-Flores, E. (2016). Phonological features of basilectal Philippine English: an exploratory study. Presented at the DLSU Research Congress 2016. 4.

[12] Salazar, D. (2017) Philippine English in the Oxford English Dictionary: recent advancements and implications for ESL in the Philippines. The Philippine ESL Journal. ELE Publishing. 19. 45-59.

[13] Stojičić, V. (2004). Sociolinguistic stimuli to development of the English lexicon - language contact and social need. Facta Universitatis. Linguistics and Literature. 3(1). 29-36.

[14] Wardhaugh, R. (2006). An introduction to sociolinguistics, 5th Ed. Blackwell Publishing

[15] Yule, G. (2010). The study of language, (4th Ed). The Cambridge University Press. 